\title{
A violência institucional em creches e pré-escolas sob a ótica das mães
}

\author{
The institutional violence in day-care and pre-schools according to mothers' view \\ La violencia institucional en guarderías y pre-escuelas según la óptica de las madres
}

\begin{abstract}
Lana Ermelina da Silva dos Santos', Maria das Graças Carvalho Ferriani'
'Universidade de São Paulo. Escola de Enfermagem de Ribeirão Preto. Programa de Pós-Doutorado. Ribeirão Preto, SP
\end{abstract}

Submissão: 05/05/2008

Aprovação: 20/12/2008

\section{RESUMO}

O objetivo desta pesquisa é conhecer a violência institucional nas creches e pré-escolas pela ótica das mães. Foi elaborada com duas abordagens: Quantitativa e Qualitativa. A coleta de dados primários foi feita pela pesquisadora por meio de entrevista e observação, e os dados Qualitativos foram coletados por entrevista gravada, fazendo-se a análise de conteúdo. Os resultados mostram Que $23,9 \%$ das mães afirmam Que existe violência contra a criança; a proporção de crianças Que não sofreu violência na creche pode ser considerada estatisticamente significante, Quando comparada às Que já sofreram, independentemente do tempo de freeüência na creche $(p=0,95)$; as mães dizem Que não sabem a causa da violência institucional; a violência física aparece com maior incidência; é mais freoüente a mãe procurar saber a causa da violência, e a menos, denunciar ao Conselho Tutelar. Cabe aos pais a proteção da criança e precisam conhecer as maneiras de protegê-la da violência infantil.

Descritores: Maus-tratos infantis; Cuidado da criança; Enfermagem pediátrica.

\section{ABSTRACT}

The objective of this research is to know the institutional violence in the day-care centers and preschools by the mothers' view. It was elaborated with two approaches: Quantitative and Qualitative. The researcher through interview and observation made the collection of primary data, and the Qualitative data werw collected by recorded interview, being made the content analysis. The results show that $23,9 \%$ of the mothers affirm that violence exists against the child; the proportion of children that didn't suffer violence in the day-care center can be considered statistically significant, when cmpared with those already suffered, independently of the time of frequency in the day-care center $(p=0,95)$; the mothers say they don't know the cause of the institutional violence; the physical violence appears with larger incidence; it is more frequent the mother to try to know the cause of theviolence, and the minus, to denounce to Guardian Council. It's compatible to the parents the child's protection and they need to know the ways of protecting them of the infantile violence.

Descriptores: Child abuse; Child care; Pediatric nursing.

\section{RESUMEN}

El objetivo de esta pesquisa es conocer la violencia institucional en las guarderías y preéscuela por la óptica de las madres. Fue elaborada con dos abordajes: cualitativa y cuantitativa. La recopilación de datos primarios fue hecha po la encuestadora por medio de entrevista, y los datos cualitativos fueron coletados por medio de entrevista grabada, haciéndose la analise de I contenido. Los resultados muestran Que $23,9 \%$ de las madres afirman que existe violencia contra el niño. La proporción de niños Que no sufrieron violencia en la guardería puede ser considerada estadísticamentesignificante, cuando comparado con las Que sufrieron, independentemente del tiempo defrecuencia en la guardeía $(p=0,95)$; las madres dicen Que no saben la causa de la violencia institucional, la violencia física aparece con mayor incidencia; es mas frecuente la madre buscar saber a causa de la violencia, $y$ a menos, denunciar al Concejo Tutelar. Compete a los padres la proteccíondel niño y precisan conocer las maneras de protegerlo de la violencia infantil.

Descriptores: Maltrato a los niños; cuidado del niño; Enfermería pediátrica. 


\section{INTRODUÇÃO}

A violência apresenta-se historicamente na sociedade, possuindo raízes macroestruturais. Apresenta várias formas e faces e encontrase diluída sob a forma das mais diversas manifestações ${ }^{(1)}$.

É preciso chamar atenção para a violência resultante da falta de acesso aos serviços necessários, da falta de Qualidade ou inadeQuação do atendimento, Que representa mais uma agressão à pessoa Que busca assistência para os diversos tipos de necessidades. Alertar para esse tipo de violência, a Qual chamamos de institucional, é muito importante, pois as pessoas estão vulneráveis aos seus efeitos ${ }^{(2)}$.

As creches e pré-escolas originaram-se na filantropia e foram criadas de acordo com a visão dos organizadores da época e Que, mesmo havendo parcas legislações, estas muitas vezes foram ignoradas. Essa trajetória gerou muitos problemas Que hoje dificultam a organização e a Qualidade do atendimento.

A violência vista na ótica da estrutura das instituições, e paralelamente considerando a história da educação infantil, parece ser tão perversa Quanto QualQuer outra modalidade de violência. Acontece por deficiência na criação e na organização das creches e pré-escolas, originando as equipes mínimas e não Qualificadas para o trabalho; falta de recursos financeiros para atender a necessidade das crianças; estruturas físicas deficientes e improvisações inadequadas para o funcionamento das instituições; ausência de proposta pedagógica e de planejamento de atividades, e além de inadeQuação do planejamento para a população atendida.

Com a adequação das creches, em relação à Lei de Diretrizes e Bases da Educação Nacional, LDB, Questões de violência institucional poderão desaparecer de forma gradual, pois surge com a Lei o inclusão do credenciamento das instituições, o Que pode ser um inibidor dos problemas Que hoje rondam as crianças institucionalizadas.

Com vistas à abordagem acima, o presente estudo tem por objetivo conhecer a violência institucional nas creches e pré-escolas pela ótica das mães Que freeüentam a instituição.

\section{METODOLOGIA}

Esta pesquisa foi realizada num município do Sul de Minas Gerais junto a seis creches, sendo Quatro públicas municipais e duas filantrópicas, as Quais atendem a uma população com iguais características.

O estudo foi elaborado por meio de duas abordagens: Quantitativa e Qualitativa.

Para a seleção das variáveis de estudo, a autora baseou-se em levantamento bibliográfico e em sua experiência nas creches relacionadas à saúde da criança. A fim de atender aos objetivos da pesquisa, foram estudadas as seguintes variáveis: tipo e conhecimento sobre violência, ações da instituição e dos pais frente à violência, envolvimento com a instituição, atitude das crianças e dos pais frente à violência.

Elaborou-se um estudo descritivo e transversal; para a coleta de dados, foi utilizado formulário elaborado com Questões estruturadas e semi-estruturadas, testados previamente, tendo como referência as variáveis selecionadas. Utilizou-se o termo de consentimento livre e esclarecido nas entrevistas com as mães.
A coleta de dados primários foi realizada pela peseuisadora, por meio de entrevistas e observação não participante, utilizandose um roteiro para obter dados de forma sistematizada, nos meses de dezembro de 2004 a fevereiro de 2005.

$\mathrm{Na}$ abordagem Qualitativa, optou-se pela pesquisa estratégica e, na coleta de dados, foi utilizada a entrevista, optou-se por utilizar a semi-estruturada por ser aquela Que parte de certos Questionamentos básicos, apoiados por teorias e hipóteses relacionadas à pesquisa e Que, seQüencialmente, oferecem amplo campo de interrogativa, fruto de novas hipóteses Que vão emergindo à medida Que se reconhecem as respostas do entrevistado ${ }^{(3)}$.

A entrevista foi gravada, seguindo os rigores das Diretrizes e Normas Regulamentadoras de Pesquisa em Seres Humanos, Resolução CNS 196/96; toda pesQuisa seguiu rigorosamente a resolução citada, sendo aprovada pelo Comitê de Ética em pesQuisa $^{(4)}$.

Para caracterização das respostas obtidas nas entrevistas, optouse por utilizar letras, conforme apresentação: $\mathrm{Mm}=$ mãe.

Para melhor compreensão do fenômeno, o método utilizado foi análise de conteúdo. Nesse contexto, fez-se a análise temática com o recorte do conjunto das entrevistas por meio de categorias projetadas sobre os conteúdos ${ }^{(5)}$.

$\mathrm{Na}$ análise dos resultados Qualitativos, visando à melhor organização e exploração dos resultados obtidos com as entrevistas, optou-se por seguir as etapas Que compreendem a pré-análise, exploração do material (onde dados foram agrupados num único grupo temático: violência institucional) e o tratamento dos resultados com a inferência e a interpretação dos resultados ${ }^{(5,6)}$.

\section{RESULTADOS E DISCUSSÃO}

Da população de mães estudadas, 23,9\% afirmam Que existe violência contra a criança e, destas, $50,0 \%$ freqüentam a creche num período de tempo igual ou menor Que 1 ano. As demais variaram entre 2 e 5 anos. Desse modo, pode-se afirmar Que a proporção de crianças Que não sofreu violência na creche pode ser considerada estatisticamente significante, Quando comparada às Que já sofreram, independente do tempo de freeüência na creche $(p=0,95)$. Esse fato não minimiza o problema, apenas vem colocar em destaque a Qualidade do serviço prestado e levantar Questionamentos com relação ao alcance dos objetivos da educação infantil.

De acordo com a Figura 1, as mães dizem Que não sabem a causa da violência institucional. Essa afirmação talvez possa desvelar a situação de impotência frente a macroquestões Que envolvem a violência.

No ambiente da creche, foi observado o comportamento dos docentes e monitores, Que, de maneira geral, parece que trabalham sempre em estresse, o Que chega a ser relatado por alguns professores Que têm dificuldades em lidar com as crianças, chegando a afirmar Que preferem o ensino fundamental e, por meio de gritos, e castigos demonstram a falta de habilidade.

Observa-se também Que as salas são cheias e as crianças, muitas vezes, carecem de atividades planejadas e de brinquedos, Que são pedaços de carrinhos, de bonecas ou jogos incompletos.

A relação número de criança por educador tem sido apontada em vários estudos como um problema Que dificulta o alcance do 


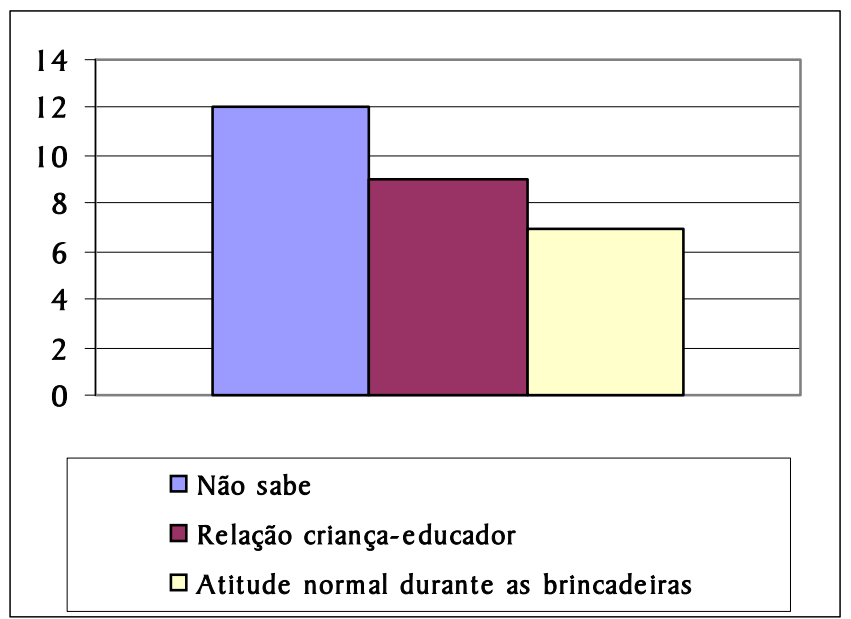

Figura 1. Causas da violência institucional por mães de crianças de creche e pré-escola de 2000 a 2003.

objetivo concreto da educação infantil. Entende-se Que essa relação favorece a violência Que, neste caso, pode ser classificada, também, como violência estrutural ou institucional, e atingir aspectos éticos do cuidar da criança. Essa relação deficitária tem se mantido no cenário nacional. Atualmente não há creches em número suficiente para atender a demanda existente e as instituições trabalham com um número de crianças acima de sua capacidade. Esse contexto fere o princípio da justiça, Quando se analisa pela ótica da bioética principialista.

A Questão ética já vem sendo discutida com relação à violência e entender e compreender a violência é imprescindível para assumir uma atitude conseQüente e efetiva na tarefa de controlar ou erradicar a violência. É necessário entender a violência como comportamento humano, suas causas e suas origens. A Psicanálise, a Antropologia, a Sociologia, a História e a Economia são fundamentais para atuar no rompimento do complexo mapa da violência.

Os dados da Tabela I demonstram a violência institucional no âmbito da creche e pré-escola, segundo o olhar das mães e cabe uma reflexão sobre esse tipo de violência: ... é aquela exercida nos próprios serviços públicos, por ação ou omissão, inclui desde a dimensão mais ampla da falta de acesso à má Qualidade dos serviços, abrange também, abusos cometidos em virtude das relações de poder desiguais entre usuários e profissional dentro das instituições, até uma noção mais restrita de dano físico intencional(2).

Mesmo após a LDB, o sistema escolar brasileiro ainda é deficitário e a pré-escola praticamente inexiste; a escola primária tem começo tardio ficando a criança, com freeüência, entregue à própria sorte até essa época, pois as mães também têm, muitas vezes, de procurar um emprego para garantir a subsistência da família. A educação não deve limitar-se apenas à transmissão de conhecimentos fundamentais, inclui o aprendizado de regras de comportamento em sociedade, de civismo, de respeito pelo outro, de conhecimento dos deveres e dos direitos do cidadão, de incentivo à inovação e à vida associativa e política local ${ }^{(7)}$.

Nesse sentido, pode ser detectada a preocupação de mães com relação à formação de hábitos, como na fala Que se segue: ... não gostei como mãe, que é de monitora e professora, fumar na creche.

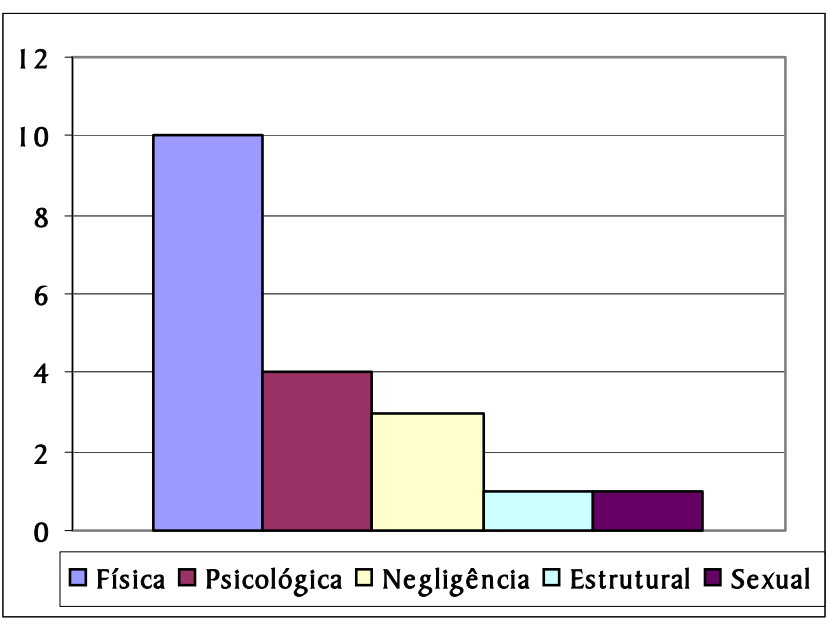

Figura 2. Tipo de violência sofrida por crianças, segundo mães nas creches e pré-escola de 2000 a 2003.

\section{A gente educa para não fumar. Se a criança vê ela acha normal} (Mn4).

Fumar dentro das creches e pré-escola foi constatado, assim como foi verificado durante o horário de sono e repouso das crianças, o monitor dormir junto com as crianças, no mesmo colchão. Essa atitude vem de encontro ao caráter vigilante da assistência à criança, além de envolver também Questões de formação de hábito e de higiene física.

Nos dados da figura 2, a violência física aparece com maior freeüência; os outros tipos com menor destaque, mas com a mesma importância. A responsabilidade das Instituições de Educação Infantil é de educar e de cuidar das crianças, Que necessitam de assistência ininterrupta, e por esta razão o atendimento deficitário prejudica o desenvolvimento. O ambiente da creche tem Que ser constantemente de equilíbrio, com educadores capazes de cuidar com atenção, carinho e conhecimento das necessidades da criança.

Outras formas de violência também precisam ser postas em discussão com a mesma seriedade, pois podem trazer malefícios Que comprometem a Qualidade da vida e futuramente podem ser multiplicadoras do problema no ambiente familiar.

Para combater a "cultura da violência, há Que se rejeitar radicalmente a adesão à violência, Quer como recurso educativo, Quer como forma de solução de conflitos. No primeiro caso, é necessário ser contra, radicalmente, ao uso de castigos físicos na educação infantil, sejam eles moderados ou imoderados, o que é chamado de "pedagogia negra". Torna-se prudente ser contra a humilhação, o ridículo como formas disciplinares, Que freqüentemente integram essa pedagogia ${ }^{(8)}$.

A violência psicológica precisa sempre ser buscada no ambiente da escola, pois produz dano à formação das crianças Que são muito susceptíveis. Durante a permanência na creche, buscou-se comportamentos violentos, verificou-se a forma da abordagem à criança, Que muitas vezes, causa constrangimento oriundo de entonação de voz e gritos freqüentes.

Quando o cotidiano da criança está submisso à intolerância, ao rancor, a reações agressivas imprevisíveis, sua capacidade de ligação é prejudicada. Tais experiências marcam a memória e a personalidade da criança e aumentam a possibilidade dela tornar- 
Tabela 1. Violência Institucional em creches e pré-escolas de 2000 a 2003.

\begin{tabular}{|c|c|c|c|}
\hline \multirow{2}{*}{ Aspectos relacionados à violência } & \multirow{2}{*}{ Respostas } & \multicolumn{2}{|c|}{ Fre@üência } \\
\hline & & $\mathrm{n}$ & $\%$ \\
\hline \multirow{2}{*}{$\begin{array}{l}\text { Criança sofreu violência na } \\
\text { creche }\end{array}$} & Sim & 18 & 19,6 \\
\hline & Não & 74 & 80,4 \\
\hline \multirow[t]{4}{*}{ Quem praticou a violência } & Outra criança & 13 & 72,3 \\
\hline & Professor & 2 & 11,1 \\
\hline & Funcionário & 2 & 11,1 \\
\hline & Não sabe & 1 & 5,5 \\
\hline A instituição comunica aos pais & Sim & 22 & 23,9 \\
\hline casos de violência & Não & 70 & 76,1 \\
\hline A criança comenta o Que & Sim & 22 & 23,9 \\
\hline acontece & Não & 70 & 76,1 \\
\hline \multirow{5}{*}{$\begin{array}{l}\text { Atitude dos pais frente à } \\
\text { violência }\end{array}$} & Procura saber a causa & 13 & 72,3 \\
\hline & É comum entre crianças & 2 & 9,9 \\
\hline & Denuncia ao Conselho Tutelar & 1 & 4,4 \\
\hline & Orienta a criança para não ser agressiva & 2 & 9,9 \\
\hline & Não faz nada & 4 & 19,8 \\
\hline \multirow{3}{*}{$\begin{array}{l}\text { lá soube se outras crianças } \\
\text { sofreram violência }\end{array}$} & Sim & 33 & 35,9 \\
\hline & Não & 58 & 63,0 \\
\hline & Não sabe & 1 & 2,1 \\
\hline \multirow[t]{4}{*}{ Quem praticou a violência } & Professor & 10 & 30,4 \\
\hline & Monitor & 5 & 15,2 \\
\hline & Criança & 4 & 12,1 \\
\hline & Não sabe & 14 & 42,4 \\
\hline
\end{tabular}

se, no futuro, um adulto agressor ${ }^{(9)}$.

Os dados da Figura 2 mostram um caso de violência sexual, o Que merece muita atenção no ambiente da escola, principalmente, em educação infantil. Esse tipo de violência origina-se da utilização irresponsável de condições como diferenças físicas e de idade, do grau de maturidade psicológica, da capacidade social e das razões Que motivam a agressão em termos interpessoais ${ }^{(10)}$.

Em casos de violência, independentemente da classificação, ações de grande vulto devem ser pensadas. Um passo importante deve ser dado pelos trabalhadores sociais para Que sejam formuladas Políticas Públicas para toda criança e adolescente e não Política de exceção, para as crianças e adolescentes em situação de "risco pessoal e social”, Que sofreram violência e Que são geralmente crianças carentes $^{(11)}$. As situações Que conferem a privação da satisfação das necessidades básicas em um determinado contexto levam ao risco pessoal e social ${ }^{(12)}$.

Ainda se fala muito sobre o "social", mas as ações Que visam à melhoria da Qualidade de vida, Quando existem, são isoladas e, no máximo, paliativas. Torna-se urgente um conjunto de ações concretas e reais, para atacar as raízes das desigualdades, da exclusão e dos conflitos sociais Que sejam submetidas a um intermitente processo de avaliação capaz de fornecer subsídios e indicadores necessários para sua continuidade, revisão crítica e revigoração $0^{(13)}$.

Retomando essa discussão, a violência estrutural ou institucional, foi referida no tocante ao número elevado de crianças e pequeno de educadores nas creches. Existem normas traçadas para esta relação, diferindo por faixa etária. Mas, no local de estudo, essa relação não é seguida e as instituições sempre atuam acima da recomendação com variações freeüentes.
Quando se depara com a violência institucional, é preocupante, por ser a creche uma instituição Que cuida de crianças de zero a 6 anos de idade; portanto a violência, nesse caso, é inaceitável, criminosa e passível de punição. Talvez por uma Questão cultural, esta realidade tem sido considerada normal e aceita ou mantém-se escondida da população e só vem à tona Quando as famílias conseguem identificar atitudes violentas, denunciar e divulgar o fato com o apoio da mídia, Que parece estar preocupada com a grande manchete e não com a proteção da criança. O fato é Que esta violência aparece de maneira velada e tem acontecido de formas diversas.

A violência institucional acomete as crianças por dar um atendimento de Qualidade precária, motivado por deficiências organizacionais, por desconhecimento de normas ou por falta de compromisso com a Qualidade da educação infantil. Por outro lado, é perversa também com os educadores, Que acabam sendo vítimas da violência por exercer sua atividade profissional com pouca Qualidade, grande desgaste, estando freqüentemente expostos ao estresse e sendo responsáveis pela Qualidade da assistência.

Outra Questão é a formação inadequada do educador infantil, o Que, muitas vezes, permite Que não se percebam os riscos a Que expõem as crianças. É necessário Que a visão da educação para a criança nessa faixa etária seja compreendida, para Que as atividades propostas se tornem interessantes e envolvam as crianças, evitando situações Que possam levar a riscos de acidentes e também de violência, tal como a fala a seguir: ...mas as crianças fogem, de uns trinta dias para cá já fugiram 10 crianças, inclusive a minha... estava passeando com a professora de mãos dadas (entre as crianças), era a última da fila, escapou e fugiu e levou mais duas com ela $(\mathrm{Mn} 3)$. 


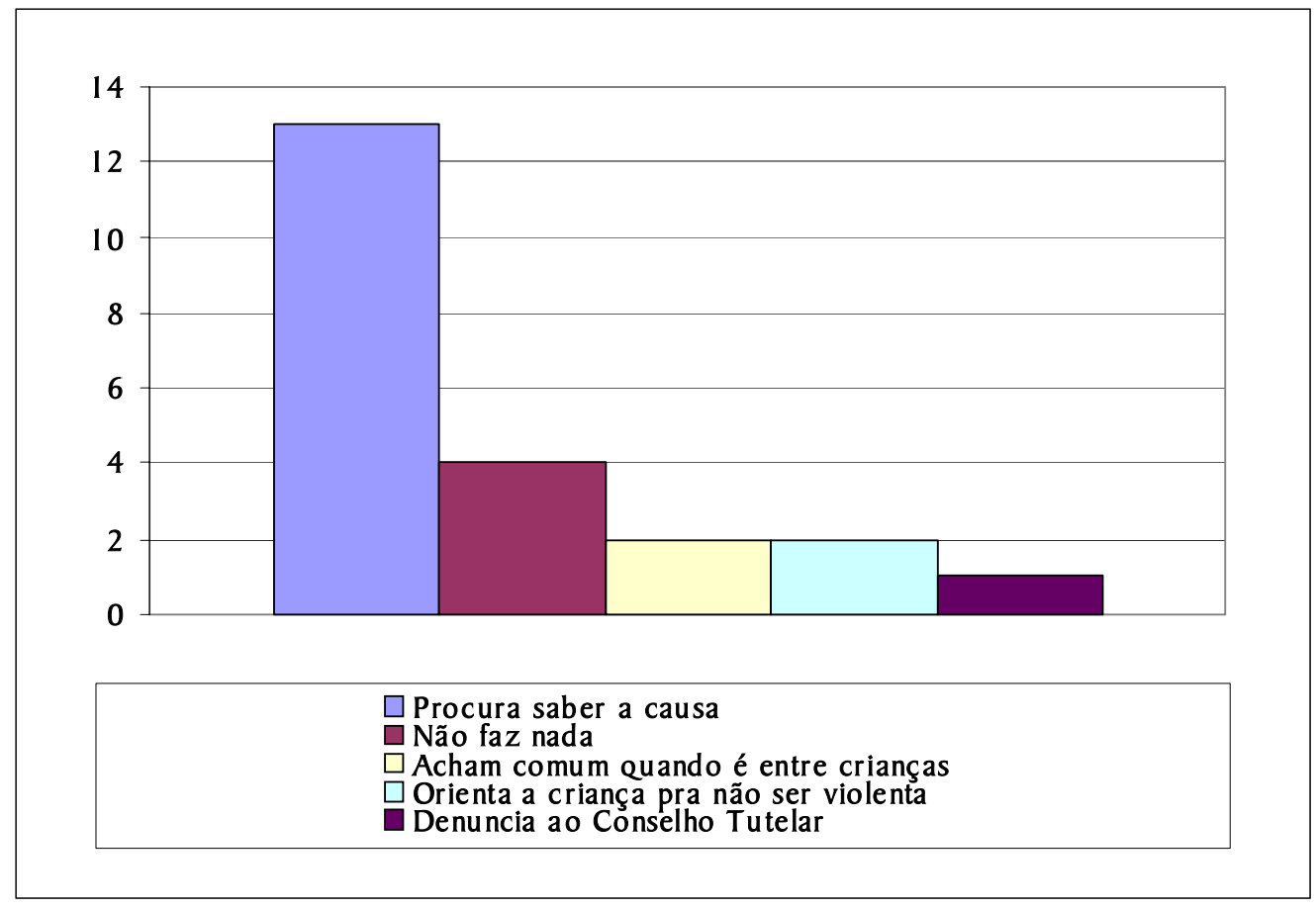

Figura 3. Atitude das mães frente à violência infantil nas creches e pré-escolas do município de Alfenas, MG, 2000 a 2003

A violência institucional é velada. Educadores, diante das dificuldades, acreditam Que fazem o melhor Que podem para atender a criança e sentem-se injustiçados por pais ou responsáveis, Quando estes se Queixam de acontecimentos violentos no ambiente da creche ou pré-escola.

Como medidas de prevenção, pais e educadores poderão ajudar a solucionar esse desafio junto às creches e pré-escolas, participando ativamente do cuidado. De maneiras diferentes, são responsáveis pelo desenvolvimento e integração da criança na sociedade, de modo a ser um adulto responsável e produtivo. Para tanto, algumas ações são sugeridas, tais como os pais procurarem conversar e observar seus filhos continuamente; em cada situação suspeita de violência deve ocorrer o contato com o dirigente da instituição e ser feita a denúncia ao Conselho Tutelar; a instituição de educação deve promover a participação de atividades, pois, fazendo-se presentes, podem oferecer, mesmo Que de forma tímida, alguma proteção à criança; favorecer a vinculação das famílias nas creches, como uma rede de apoio; levar a discussão da violência infantil para dentro da creche e da pré-escola.

Existe no Brasil legislação de proteção à criança, e, aQui, destacase o Estatuto da Criança e do Adolescente, Lei n 8.069 de 13 de julho de 1990, Que tem se tornado realidade de forma gradativa. Embora já esteja contemplada na referida Lei a responsabilidade dos pais junto aos filhos menores, no Que se refere a sustento, guarda e educação e também à manutenção da criança na família, os pais ressentem de uma melhor organização social, o Que possibilitará cuidar de seus filhos, podendo dar a eles maior segurança em casos de violência infantil, em QualQuer ordem, seja ela institucional ou não ${ }^{(14)}$.

A de atitude tomada pelas mães frente à violência institucional nas creches e pré-escolas pode ser uma ação inibidora. $\mathrm{O}$ envolvimento com a instituição e maior participação nas ações da escola pode minimizar o problema e favorecer a devida proteção Que a família deve oferecer para a criança.

Segundo os dados da Figura 3, o mais freeüente é procurar saber a causa, e a menos freqüente, denunciar ao Conselho Tutelar. Cabe aos pais a proteção da criança e, por isso, precisam conhecer as maneiras de proteger a criança da violência infantil. As ações parecem tímidas frente a um problema tão sério. Talvez o medo de perder uma vaga na creche, com grande demanda e o desemprego, façam com Que recuem diante da violência institucional.

A falta de informação ou a condição social pode contribuir para a passividade frente à agressão entre crianças. Os dados demonstram Que os pais as orientam para não serem violentas e Que acham comum esse comportamento. É sabido Que muitas reproduzem o ambiente familiar, mas é também um problema Que necessita de instrumentos para ser solucionado; os educadores podem ser o ponto de partida para o início de um trabalho com as famílias.

É grande a preocupação do Ministério da Saúde em relação ao problema; a carência de serviços ou respostas sociais adequados e a intervenção apenas em alguns casos constituem um obstáculo, ou retardo na resolução do problema. A busca de novas formas de ações para alcançar soluções compatíveis deve persistir como proposta. Os instrumentos jurídicos, o sistema de proteção e o sistema punitivo não têm conseguido diminuir a incidência da violência ou amenizar os seus efeitos ${ }^{(15)}$.

Uma série de medidas precisa ser tomada para começar a enfrentar a Questão: notificar, estudar cada caso, avaliar as características da violência contra a criança no município, planejar ações de prevenção e retaguarda. O necessário é não se calar, ou seja, denunciar, notificar ou registrar. 
A legislação sobre maus-tratos no Brasil tem adotado como parâmetro o modelo americano, no Que diz respeito à obrigatoriedade de notificar estabelecida para profissionais, à necessidade de encaminhar a notificação a um órgão definido por lei e à punição para o profissional Que não notificar. Contudo temse uma rede de serviços aQuém do necessário, com poucos regulamentos e com a ausência de mecanismos legais de proteção aos profissionais encarregados de notificar.

Outro fator determinante para o fim da violência institucional é a definição clara de recursos para a educação infantil e o conhecimento pleno por parte das secretarias de educação dos municípios de Que esta etapa da educação básica é mais onerosa. Esse entendimento poderá fazer com Que o planejamento seja mais criterioso e possibilite uma implementação de acordo com as necessidades da criança até 6 anos de idade.

\section{CONSIDERAÇÕES FINAIS}

A temática da violência infantil é complexa e de difícil abordagem.
Dificilmente se consegue fazê-la com pais, responsáveis e educadores. Todos, num primeiro momento, parecem desconhecer o problema em ambientes Que possam comprometê-los. Afirmam, Quase Que de forma unânime, Que conhecem a violência contra a criança, mas com freqüência, em outra localidade Que não a sua casa ou a sua escola, ou então dizem Que têm conhecimento apenas pela mídia.

Neste estudo, a proporção de criança Que não sofreu violência na creche pode ser considerada estatisticamente significante, Quando comparada às Que já sofreram, independentemente do tempo de freeüência na creche $(p=0,95)$. Esse fato não minimiza o problema, apenas vem colocar em destaQue a Qualidade do serviço prestado e a necessidade de melhorias.

A atitude mais freqüente dos pais frente à violência é procurar saber a causa da violência e a de menor freqüência é a denúncia ao Conselho Tutelar.

Entende-se que as creches e pré-escolas devem buscar recursos na comunidade para traçar estratégias de apoio às crianças e às famílias Que convivem com a violência infantil, em vários setores, tais como, saúde, educação, assistência social e judiciária.

\section{REFERÊNCIAS}

I. Cruz Neto O, Moreira MRA concretização de políticas públicas em direção à prevenção da violência estrutural. Ciência Saúde Coletiva 1999; 4(1): 33-52.

2. Ministério da Saúde (BR). Políticas nacional de redução da morbimortalidade por acidentes e violências. Brasília: Ministério da Saúde; 2002.

3. Ministério da Saúde (BR). Cadernos de atenção básica. Violência intrafamiliar - orientações para a prática em serviço. Brasília: Ministério da Saúde; 2002.

4. Triviños ANS. Introdução à pesquisa em ciências sociais: a pesquisa Qualitativa em educação. São Paulo: Atlas; 1985.

5. Ministério da Saúde. Conselho Nacional de Saúde. Resolução $\mathrm{n}^{\circ}$ 196, de 10 de outubro de 1996. Diretrizes e normas regulamentadoras de pesquisa envolvendo seres humanos. Bioética 1996.

6. Bardin L. Análise de conteúdo. Lisboa: Edições 70; 1979.

7. Minayo MCS. O desafio do conhecimento: pesquisa Qualitativa em saúde. São Paulo: Hucitec; 1996.

8. Chesnais ICA violência no Brasil. Causas e recomendações políticas para a sua prevenção. Ciência Saúde Coletiva 1999; 4; (1):148-52.

9. Fundo das Nações Unidas para a Infância - 10 Medidas básicas para a infância brasileira. São Paulo: UNICEF; 1994.

10. Ribeiro MA, Ferriani MGC, Reis IN. Violência sexual contra crianças e adolescentes: características relativas à vitimização nas relações familiares. Cad Saúde Pública 2004; 20: 82-96.

11. Vendruscolo TS. Políticas e prioridades políticas: a experiência de Ribeirão Preto no atendimento à criança e ao adolescente, vítimas de violência doméstica. Ribeirão Preto: Universidade de São Paulo; 2004.

12. Costa ACG. É possível mudar: a criança e o adolescente e a família na política social do município de São Paulo. São Paulo: Melhoramentos; 1993.

13. Cruz Neto O, Moreira MR. A concretização de políticas públicas em direção à prevenção da violência estrutural. Ciência Saúde Coletiva 1999; 4(1): 22-38.

14. Azevedo MA, Guerra VA. Violência doméstica na infância e na adolescência. São Paulo: L.C. Cultura; 1995.

15. Ministério da Saúde (BR). Série C. projetos, programas e relatórios. Mostra sociedade viva. Violência e saúde. Brasília: Ministério da Saúde; 2004. 